Tema: Aciaria Elétrica

\title{
INFLUÊNCIA DA PROPORÇÃO ENTRE AS VAZÕES DE OXIGÊNIO E GÁS NATURAL DO SISTEMA DE INJEÇÃO DE UM FORNO ELÉTRICO A ARCO NO CONSUMO DE ENERGIA TOTAL*
}

\author{
Daniel Rossi $i^{1}$ \\ Wagner Viana Bielefeldt $t^{2}$ \\ Antônio Cezar Faria Vilela ${ }^{3}$
}

\begin{abstract}
Resumo
Em aciarias elétricas, o consumo dos insumos tem impacto importante na composição do custo final do aço, dos quais se destaca o consumo de energéticos utilizados no forno elétrico a arco, que pode representar até $30 \%$ do custo operacional de uma aciaria. Para quantificar o aporte desses diferentes tipos de energia é utilizado o indicador de consumo de energia total FEA + FP, que associa fatores de equivalência a cada tipo de energético de forma a transformar sua unidade de medida para a unidade base de $\mathrm{kWh} / \mathrm{t}$. Nesse trabalho foi realizado um teste no formato de projeto de experimentos, variando-se as vazões de gás natural e/ou oxigênio em um dos modos de queimador e em três modos de lança a fim de modificar suas proporções $\mathrm{O}_{2} / \mathrm{GN}$ e avaliar o impacto no consumo de energia total.

Palavras-chave: Energia total; Eficiência energética; Injeção de gases; Processo de FEA.

\section{INFLUENCE OF OXYGEN AND NATURAL GAS RATIO OF AN ELECTRIC ARC FURNACE INJECTION SYSTEM IN TOTAL ENERGY CONSUMPTION}

\begin{abstract}
In electric steelmaking, consumption of inputs plays an important role on the final billet cost, with particular emphasis to the energy consumption in the electric arc furnace, which can represent up to $30 \%$ of the operational cost in a melt shop. To quantify the contribution of different types of energy in EAF, it is used the performance indicator of total energy consumption, which associates equivalency factors for each type of energy, so that their measurement unit can be transformed to the base unit $\mathrm{kWh} / \mathrm{t}$. In this work, a test was conducted on a design of experiments format, varying the flow of natural gas and/or oxygen in a burner mode and in three lance modes, in order to modify their $\mathrm{O}_{2} / \mathrm{GN}$ ratio and evaluate the impact in total energy consumption.
\end{abstract}

Keywords: Total energy; Energy efficiency; Gas injection; EAF process.

1 Engenheiro Metalúrgico, Engenheiro de Processo, Gerdau, Sapucaia do Sul, Rio Grande do Sul, Brasil.

2 Engenheiro Metalúrgico, Prof. Dr., PPGE3M, DEMET, Universidade Federal do Rio Grande do Sul, Porto Alegre, Brasil.

3 Engenheiro Metalúrgico, Prof. Dr.-Ing., PPGE3M, DEMET, Universidade Federal do Rio Grande do Sul, Porto Alegre, Brasil.

* Contribuição técnica ao 45 Seminário de Aciaria - Internacional, 25 a 28 de maio de 2014, Porto Alegre, RS, Brasil. 


\section{INTRODUÇÃo}

O processo do forno elétrico a arco consome uma quantidade muito grande de recursos, tais como, energia elétrica, energia química (oxigênio, gás natural, materiais carbonosos e óleos) e altos volumes de água de refrigeração para fundir a carga metálica e aquecê-la até sua temperatura de vazamento. Pode-se dizer que é um processo intensamente energético. Dessa forma, um dos maiores desafios dentro de aciarias elétricas é fazer com que, dentro de determinadas condições, consiga-se aperfeiçoar o processo de um forno elétrico a arco para que tenha alta produtividade e baixo custo, utilizando a menor quantidade possível de recursos.

A máxima produtividade pode ser atingida utilizando a maior quantidade de energia elétrica e química disponível, uma vez que quanto maior a potência (elétrica e química) de um forno, mais rapidamente o metal será fundido. No entanto, o que muitas vezes se questiona é quanto dessa potência que está sendo disponibilizada está realmente fundindo o metal e quanto está sendo perdida, pois para ser eficiente, um processo necessita ter baixas perdas.

Desde os anos 60 a evolução na operação dos fornos elétricos tem resultado em grandes avanços no consumo de insumos e aumento de produtividade (Figura 1), porém há muito trabalho ainda a ser realizado no campo de redução de perdas, uma vez que a eficiência energética média de um FEA normalmente está entre 55 a 65\%. Buscando alternativas para reduzir essas perdas, nesse trabalho foram testadas modificações nas vazões do sistema de injeção de gases com o objetivo de avaliar o impacto na eficiência energética do forno. Como parâmetro para quantificar essa eficiência, foi utilizado o indicador de consumo de energia total.

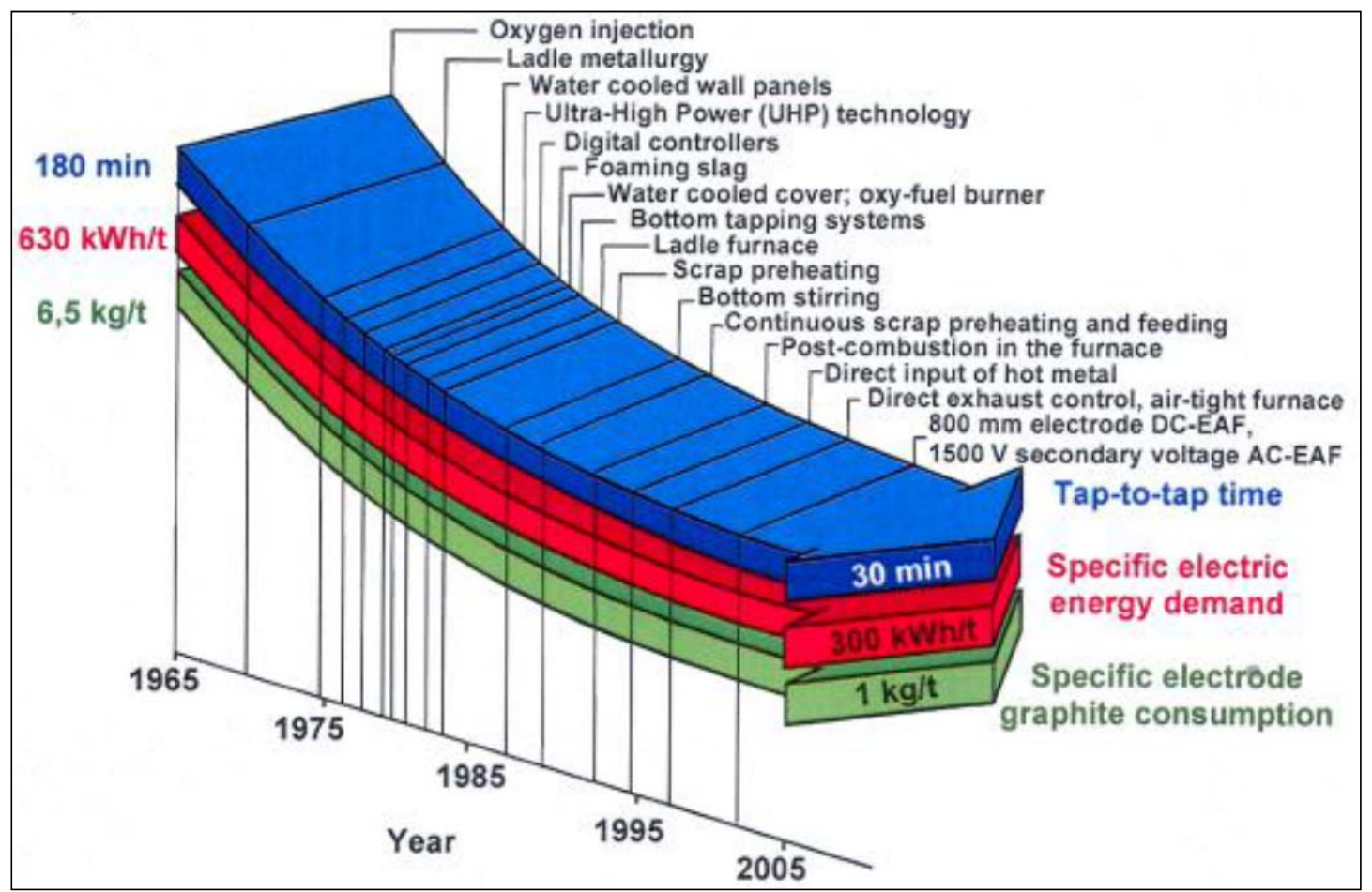

Figura 1. Evolução no desempenho de fornos elétricos a arco [1].

* Contribuição técnica ao 45 Seminário de Aciaria - Internacional, 25 a 28 de maio de 2014, 


\section{ENERGÉTICOS NO FORNO ELÉTRICO A ARCO}

\subsection{Balanço Energético no FEA}

Através de um diagrama de balanço energético (Figura 2) [2], observa-se que a energia introduzida no forno elétrico a arco é fundamentalmente composta de energia elétrica e uma parcela de energia química. A energia elétrica corresponde a maior parte do consumo total de energia e é introduzida pelos eletrodos através do arco elétrico, que ocorre pela passagem da corrente entre o cátodo e o ânodo postos em contato e submetidos a potenciais elétricos diferentes. A posição do eixo do arco e seu comprimento determinam a direção do fluxo de calor. O volume do arco, que confere as condições de transferência de calor, é basicamente definido por duas variáveis: tensão (define o comprimento do arco) e corrente (define a seção transversal do arco). A maior parte da transferência de calor do arco para a carga ocorre por irradiação, uma vez que essa é proporcional à temperatura na quarta potência [3].

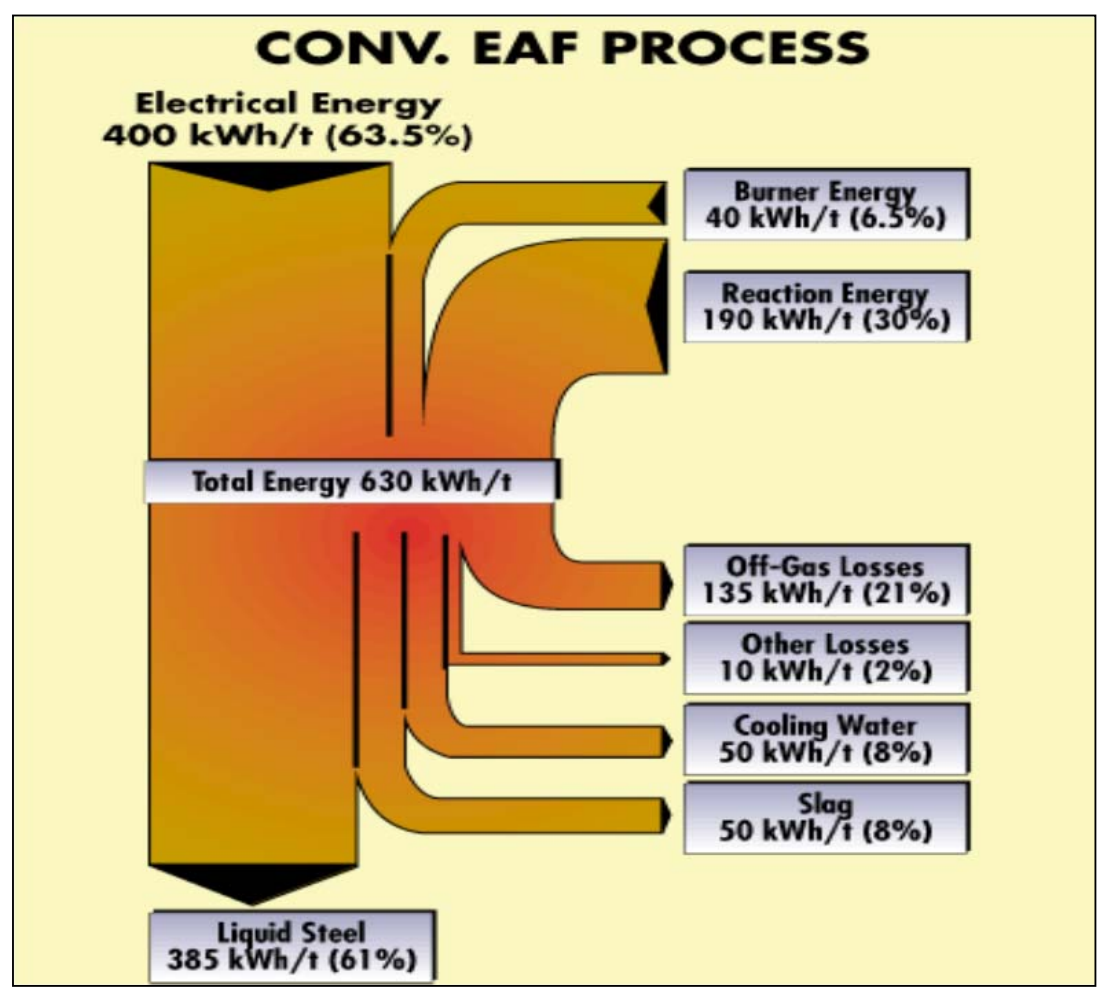

Figura 2. Balanço energético de um FEA [2].

Com o avanço tecnológico nas operações com fornos de ultra alta potência (UHP), que operam com altos comprimentos de arco, o uso de fontes de energia química tornou-se popular, visando principalmente:

- Formação da escória espumante: formada por reações oriundas de parte da energia química fornecida ao FEA, visa aumentar a eficiência do arco (Figura 3) e reduzir as perdas por irradiação para os elementos refrigerados e refratários [4].

* Contribuição técnica ao 450 Seminário de Aciaria - Internacional, 25 a 28 de maio de 2014, 

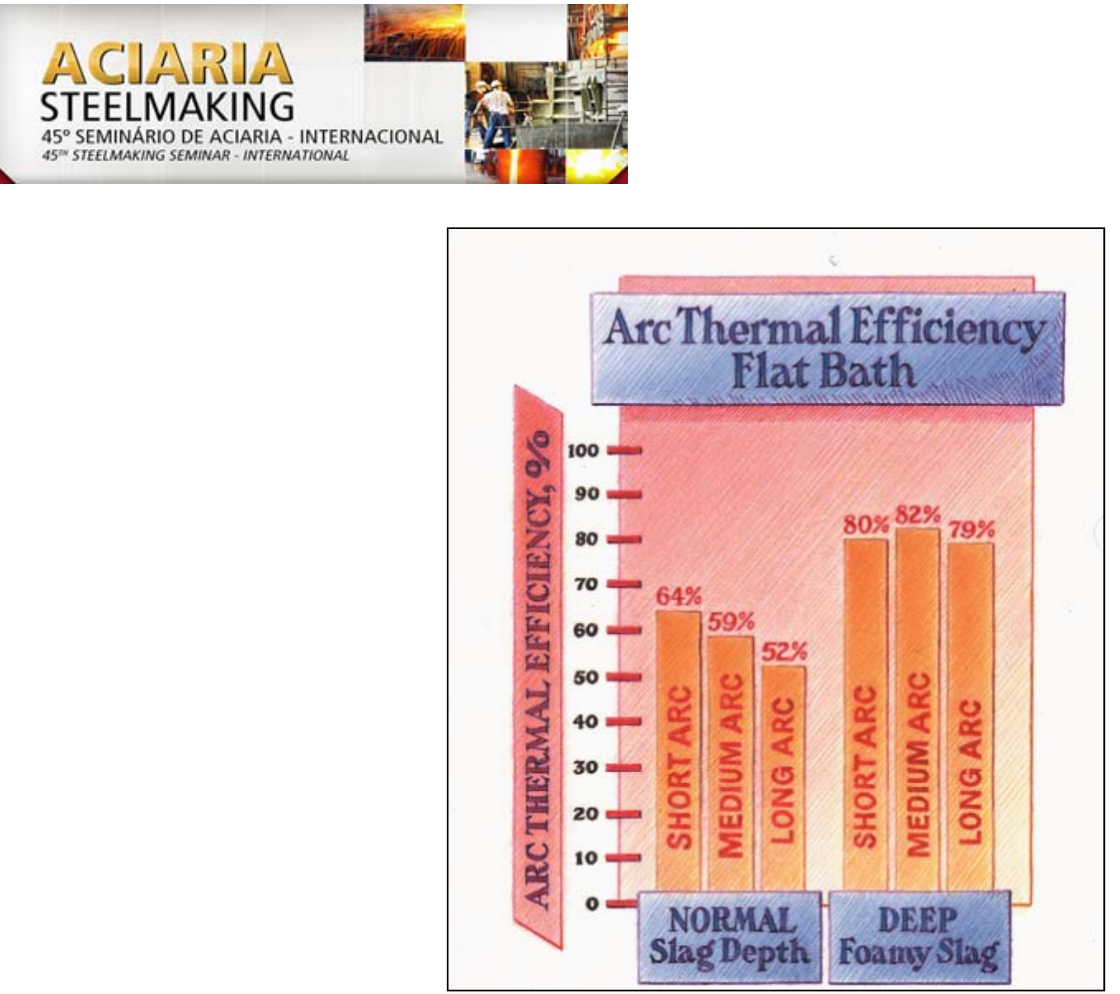

Figura 3. Eficiência do arco elétrico em função da espumação da escória [4].

- Minimização do efeito dos pontos frios: formados nas regiões onde a incidência de irradiação do arco dos eletrodos é baixa (Figura 4) e, consequentemente, a taxa de fusão é lenta. A redução desses pontos propicia um aumento substancial de produtividade nos fornos.

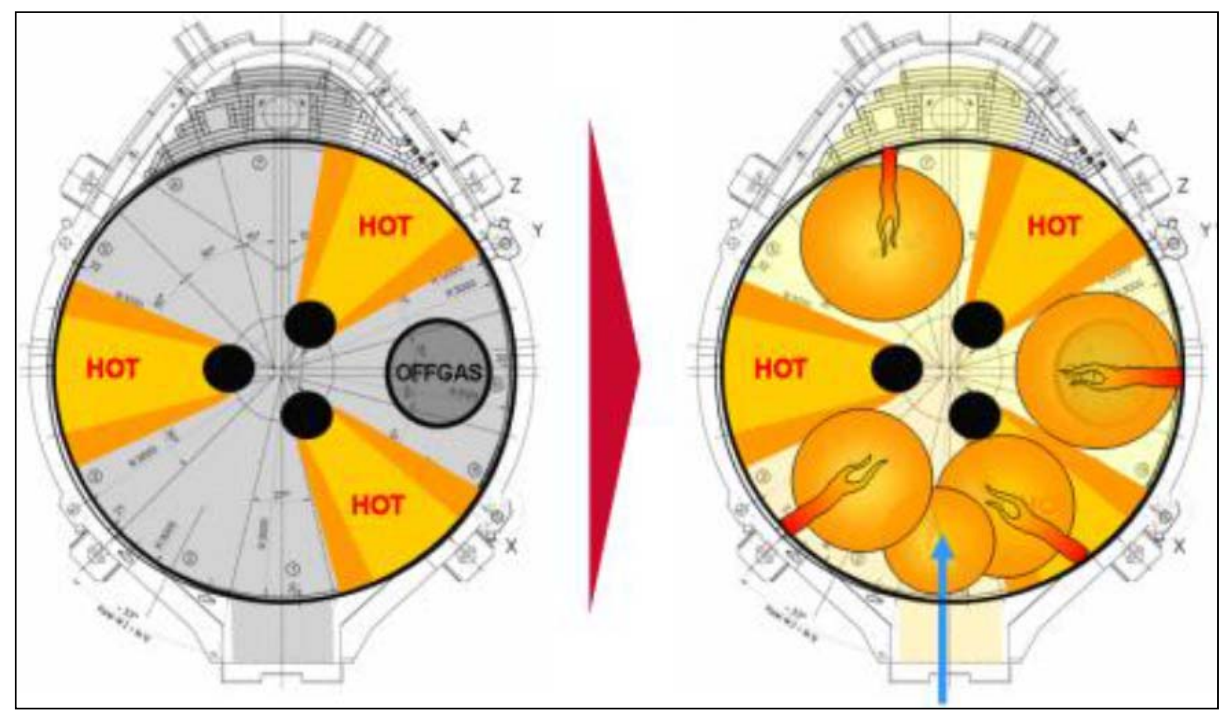

Figura 4. Posicionamento de injetores e queimadores no FEA.[5]

O posicionamento estratégico dos injetores e/ou queimadores propicia uma fusão ou "descida" uniforme da sucata da parede do forno, acelerando a condição de estabilidade do arco para uma fusão mais rápida e com menor consumo de energia elétrica. Assim, a energia química invariavelmente complementa a energia elétrica. As principais fontes de energia química em um forno elétrico são:

- Reações de oxidação dos elementos presentes na carga fria;

- Injeção e/ou carregamento de materiais carburantes;

- Combustão em queimadores com gases e/ou óleos;

- Queima de gases provenientes da combustão incompleta do carbono via injeção de oxigênio (pós-combustão).

* Contribuição técnica ao $45^{\circ}$ Seminário de Aciaria - Internacional, 25 a 28 de maio de 2014, 


\subsection{Injeção de Gás Natural Através de Queimadores Oxi-Combustível}

Queimadores oxi-combustível são normalmente utilizados nas paredes de fornos para acelerar a fusão da sucata, especialmente nos pontos frios entre os eletrodos. Enquanto a chama está próxima da sucata, sua eficiência é alta e a transferência de energia ocorre principalmente por condução. À medida que há menos sucata na região próxima do queimador e o modo de transferência passa a ser por irradiação, a eficiência do mesmo cai significativamente (Figura 5). Em geral, a eficiência de um queimador é maior que 50\% apenas no primeiro terço de cada carregamento [5].

Para o caso de queimadores que utilizam como combustível o gás natural, a queima desse gás ocorre segundo a reação: $\mathrm{CH}_{4}+2 \mathrm{O}_{2} \rightarrow \mathrm{CO}_{2}+2 \mathrm{H}_{2} \mathrm{O}+\mathrm{CALOR}$.

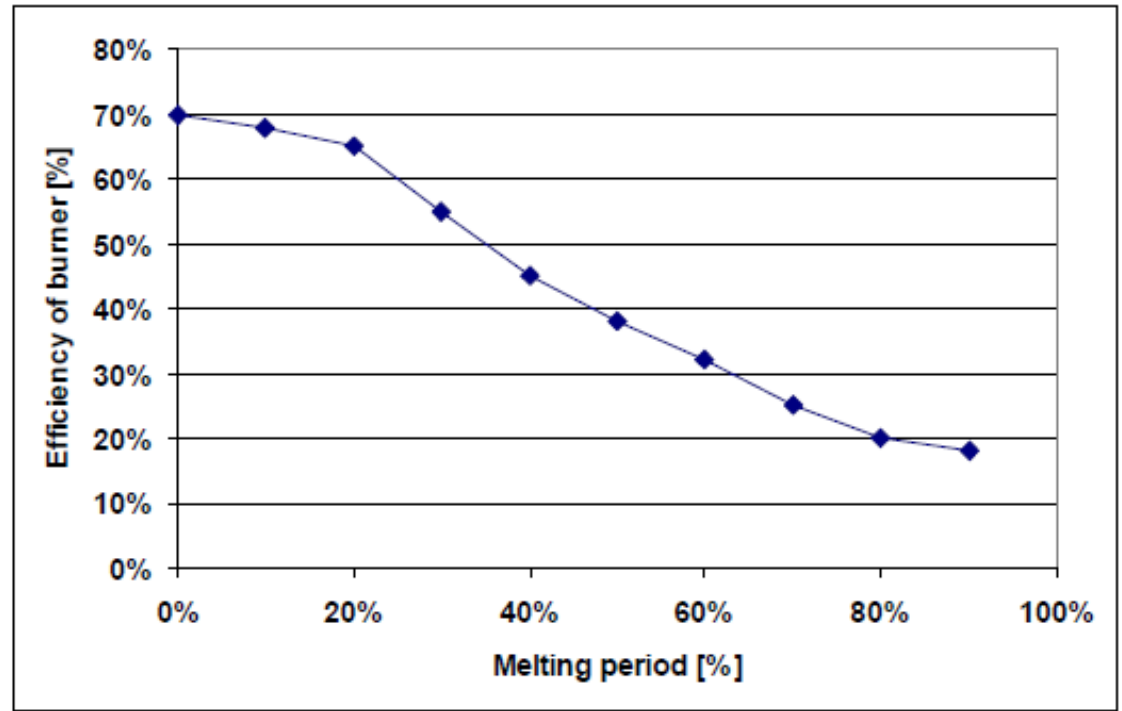

Figura 5. Eficiência de queimadores no período de fusão [5].

Grande parte dos fornos modernos utiliza a tecnologia de injetores multifuncionais, que funcionam tanto como queimadores quanto como injetores de oxigênio em modo lança para descarburação. Esses equipamentos possuem três linhas de gases associadas: uma linha de oxigênio principal, uma linha de oxigênio secundário e uma linha de gás natural. O oxigênio utilizado para a queima do gás natural é normalmente dividido entre as duas linhas.

A razão entre as vazões de oxigênio e gás natural no injetor podem ser alteradas. Para vazão total de oxigênio igual a duas vezes a vazão de gás natural, é formada uma chama denominada estequiométrica. Quando se aumenta a razão entre essas vazões, pode-se obter uma chama oxidante. Quando a vazão de oxigênio for menor que duas vezes a vazão de gás natural, poderá então ocorrer queima apenas parcial do metano.

Com relação à razão entre as vazões de oxigênio principal e oxigênio secundário em modo queimador, segundo Opfermann [5], é possível obter diferentes formas de chama sem alterar a potência do queimador, que é definida pela vazão de gás natural, ou a vazão total de oxigênio. Isso é especialmente interessante quando se deseja adequar a chama do queimador a diferentes etapas do processo sem alterar o consumo total dos gases.

* Contribuição técnica ao 45 Seminário de Aciaria - Internacional, 25 a 28 de maio de 2014, 


\subsection{Injeção de Oxigênio Através de Injetores Multifuncionais de Jato Coerente}

A função do oxigênio injetado em modo lança é fornecer energia através de reações com os elementos presentes na carga fria, principalmente carbono, ferro, silício, fósforo e manganês. Através dessa injeção pode ser obtida, quando feita juntamente com a injeção de carbono, a escória espumante e seus benefícios.

Os jatos supersônicos podem ser classificados em dois tipos: coerentes e sem coerência (convencionais). O jato coerente é aquele que consegue manter sua forma inicial por uma distância maior a partir do bico do injetor (Figura 6).

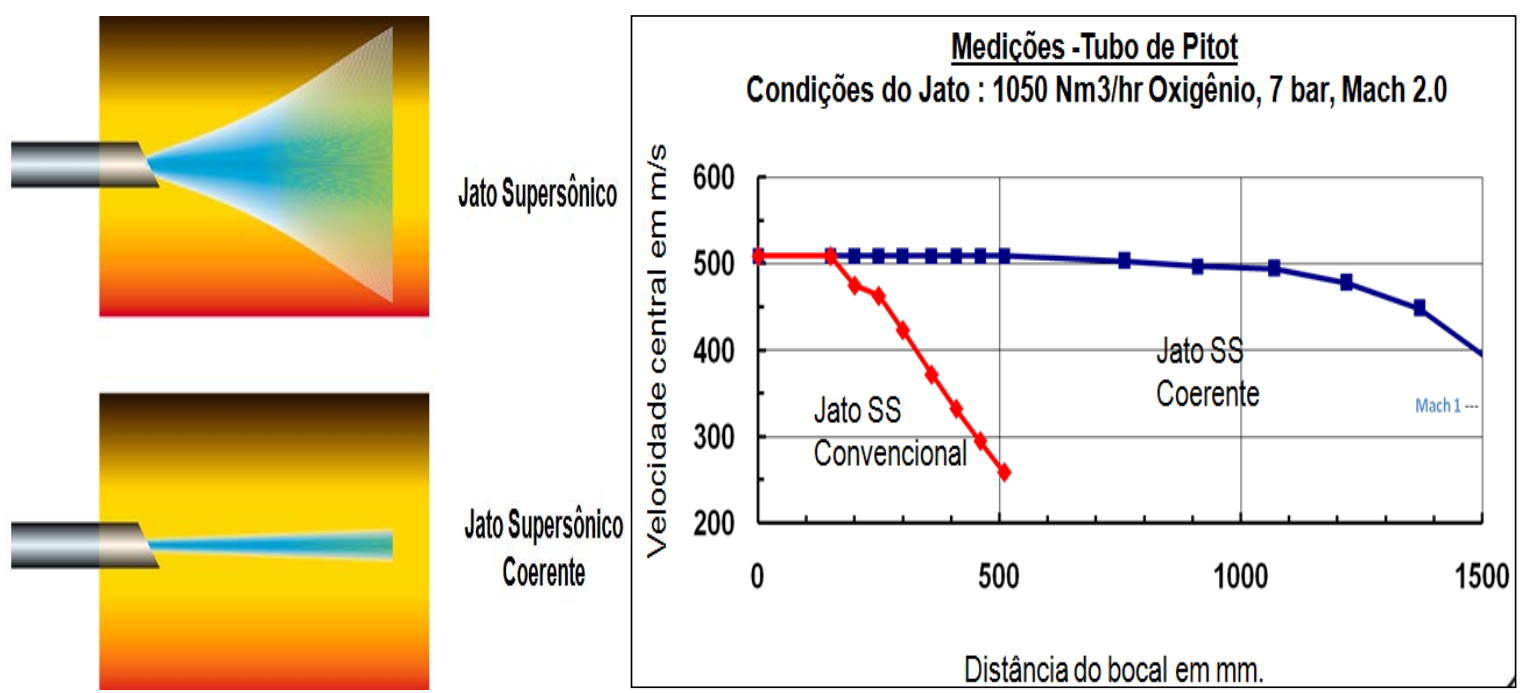

Figura 6. Jato supersônico convencional e jato coerente [6].

Para que um jato consiga penetrar no banho e reagir com seus elementos sem gerar grande quantidade de respingos de aço/escória, o mesmo deve possuir alta penetração, que é fortemente influenciada por: velocidade, coerência do jato e o momento (massa e velocidade).

Uma das principais características do jato supersônico é que a distância que ele se mantém coerente depende da temperatura do meio onde se propaga. Quanto menor a temperatura do meio maior será o atrito do jato com o ar, fazendo que o mesmo perca a sua forma inicial tubular e diminua sua velocidade, uma vez que a coerência do jato é inversamente proporcional à raiz quadrada da relação da densidade do gás ambiente pelo gás do jato. Dessa forma, injetores modernos utilizam o conceito de chama shroud, que cria uma proteção para o oxigênio principal através da queima do gás natural com o oxigênio de proteção. A chama shroud cria um meio de baixa viscosidade, fazendo com que o jato não entre em contato direto com a atmosfera do forno evitando a formação de alto atrito e perda de coerência (Figura 7).

* Contribuição técnica ao 45 Seminário de Aciaria - Internacional, 25 a 28 de maio de 2014, 

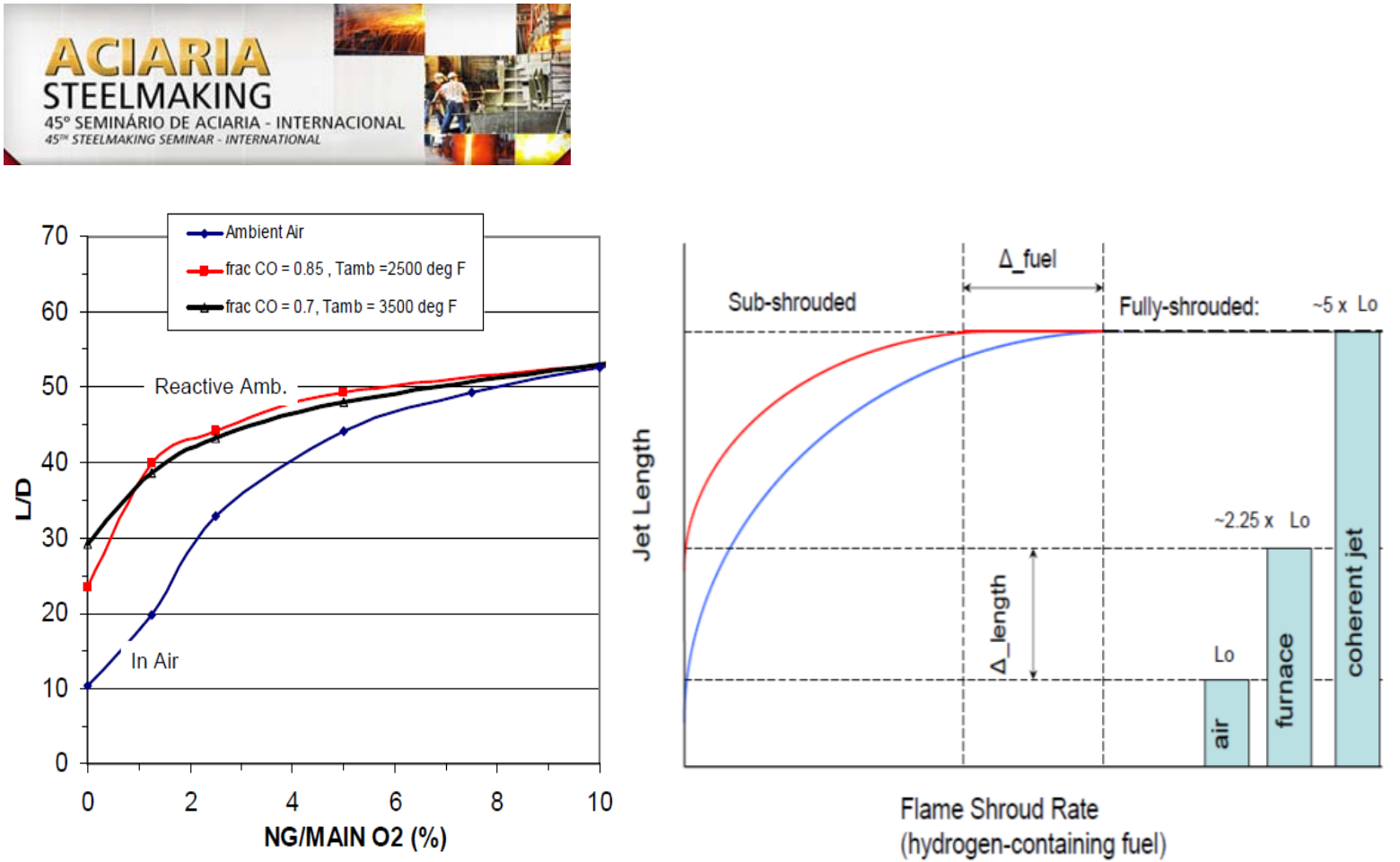

Figura 7. Efeito do ambiente e chama shroud em jatos de oxigênio [7]

\section{MATERIAL E MÉTODOS}

\subsection{Equipamentos Utilizados}

Para a realização dos testes foi utilizado um forno elétrico a arco de corrente alternada com transformador de 26 MVA e peso médio de corrida de 21 toneladas. O forno é equipado com um manipulador de lanças com duas varas de injeção de oxigênio e uma de injeção de coque, além de dois injetores multifuncionais de parede, com queimadores operando com gás natural. O oxigênio utilizado possui pureza média de $92 \%$. Os injetores possuem três modos de injeção quando utilizados em modo queimador e outros três em modo lança.

\subsection{Coleta de dados}

Foram coletados e monitorados dados de processo de 240 corridas e retiradas amostras de escória a cada 5 corridas de forma padronizada para análise por fluorescência de raios $X$. Corridas que apresentaram algum desvio ou problema de processo atípico não foram contabilizadas, bem como as duas primeiras corridas após as partidas do forno e a última corrida de cada dia onde há secagem do distribuidor no lingotamento contínuo. Após essas considerações, restaram 208 corridas que foram efetivamente utilizadas para os resultados do teste.

\subsection{Método de Realização do Teste}

Foi realizado um teste no formato de projeto de experimentos (DOE) para avaliar o impacto de diferentes setpoints de vazão de gás natural na operação de um dos modos queimador e de três modos lança. As alterações feitas em relação à operação base foram:

- Redução da vazão de gás natural em 30\% e aumento da vazão total de oxigênio de um dos modos queimador de forma a trabalhar com relação $\mathrm{O}_{2} / \mathrm{GN}$ de $3,5: 1$;

- Modificação das vazões de gás natural nos modos lança para 5\% da vazão do oxigênio principal.

Os cenários testados no DOE podem ser visualizados na Tabela 1. Foram testadas 30 corridas em cada cenário e mais 30 corridas de réplica, conforme a metodologia

* Contribuição técnica ao $45^{\circ}$ Seminário de Aciaria - Internacional, 25 a 28 de maio de 2014, 


\section{ACJARJA}

estatística. Foram formados 8 blocos de 30 corridas cada que foram testados aleatoriamente. Foi utilizado o software Minitab para o tratamento estatístico dos dados e obtenção dos resultados.

Tabela 1. Cenários testados no DOE

\begin{tabular}{|c|c|c|c|}
\hline Cenários & Vazão $G N$ modo queimador & Razão $\mathrm{O}_{2} / G N$ modo queimador & Vazão GN modos lança \\
\hline 1 & base & $2: 1$ & 0,1 x vazão $\mathrm{O}_{2}$ principal \\
\hline 2 & base & $2: 1$ & 0,05 x vazão $\mathrm{O}_{2}$ principal \\
\hline 3 & $0,7 \times$ base & $3,5: 1$ & 0,1 x vazão $\mathrm{O}_{2}$ principal \\
\hline 4 & $0,7 \times$ base & $3,5: 1$ & 0,05 x vazão $\mathrm{O}_{2}$ principal \\
\hline
\end{tabular}

A vazão total de oxigênio foi igualmente distribuída entre as linhas principal e secundária de cada injetor.

A regulagem elétrica e química (exceto alterações do teste) do forno foi igual para todos os cenários.

A carga fria utilizada em todos os cenários foi a mesma e não houve precipitação pluviométrica significativa durante a produção das corridas.

Para calcular o consumo de energia total foi escolhida a fórmula que é utilizada internamente no Grupo Gerdau para o cálculo desse indicador. Os diversos tipos de insumos têm fatores de equivalência associados, conforme dados da Tabela 2. 0 consumo de cada insumo é multiplicado pelo seu fator de equivalência. O somatório das multiplicações de cada insumo resulta no valor de consumo de energia total em $\mathrm{kWh} / \mathrm{t}$

Devido ao caráter confidencial dos dados industriais e das informações contidas no teste, a apresentação dos resultados foi feita de modo comparativo, não utilizando valores reais de processo, produção e/ou resultados.

Tabela 2. Insumos e fatores de equivalência para a base kWh/t

\begin{tabular}{|l|c|}
\hline \multicolumn{1}{|c|}{ Insumo } & Fator de Equivalência \\
\hline Energia Elétrica (kWh/t) & 1,00 \\
\hline Carvão Vegetal $(\mathrm{kg} / \mathrm{t})$ & 8,14 \\
\hline Coque de Petróleo $(\mathrm{kg} / \mathrm{t})$ & 8,37 \\
\hline Gás de Alto-Forno $\left(\mathrm{Nm}^{3} / \mathrm{t}\right)$ & 1,10 \\
\hline Gás de Aciaria LD (Nm³/t) & 2,02 \\
\hline Gás de Refinaria (Nm³/t) & 10,47 \\
\hline Gás Natural $\left(\mathrm{Nm}^{3} / \mathrm{t}\right)$ & 10,00 \\
\hline GLP $(\mathrm{kg} / \mathrm{t})$ & 13,95 \\
\hline Óleo Pesado $(\mathrm{kg} / \mathrm{t})$ & 11,05 \\
\hline Pneus $(\mathrm{kg} / \mathrm{t})$ & 7,64 \\
\hline Sucata $(\mathrm{kg} / \mathrm{t})$ & 0,09 \\
\hline Gusa Líquido $(\mathrm{kg} / \mathrm{t})$ & 0,52 \\
\hline Gusa Sólido $(\mathrm{kg} / \mathrm{t})$ & 0,28 \\
\hline Ferro Esponja / DRI $(\mathrm{kg} / \mathrm{t})$ & 0,04 \\
\hline
\end{tabular}

\section{RESULTADOS E DISCUSSÃO}

Os resultados obtidos são mostrados em valores percentuais (Figura 8).

\footnotetext{
* Contribuição técnica ao 45 Seminário de Aciaria - Internacional, 25 a 28 de maio de 2014,
} 


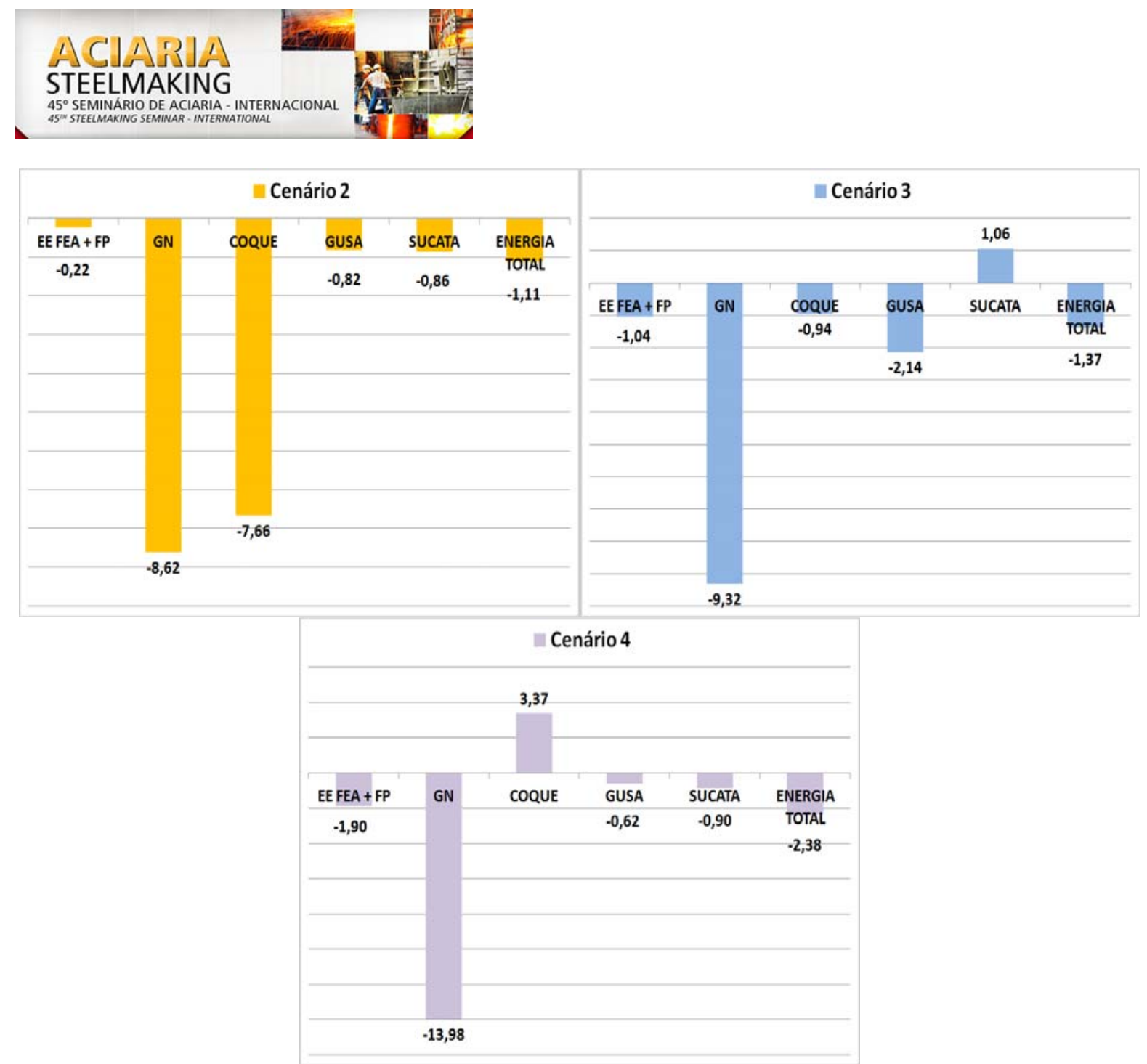

Figura 8. Comparativo de resultado em relação ao cenário 1 (base).

A modificação da relação $\mathrm{O}_{2} / \mathrm{GN}$ no modo queimador para 3,5:1 resultou em redução significativa no consumo de energia elétrica nos dois cenários em que foi aplicada (cenários 3 e 4), mesmo que a vazão de gás natural tenha sido reduzida. Thomson et al. [8] também obteve redução no consumo de energia elétrica quando testou relação de $\mathrm{O}_{2} / \mathrm{GN}$ de 8:1 em comparação a uma base 3:1. Em seu teste, utilizou um forno equipado com analisador de gases e concluiu que a redução no consumo de energia elétrica foi atribuída, principalmente, a uma maior combustão dos gases presentes dentro do forno pelo oxigênio em excesso injetado através dos queimadores, que acelerou a fusão, formação da escória espumante e o aumento da temperatura do banho. Foi evidenciado um significativo aumento na taxa de póscombustão nas corridas.

A alteração da proporção $\mathrm{O}_{2} / \mathrm{GN}$ gerou uma redução de $9,32 \%$ no consumo de gás natural, fato que contribuiu fortemente para a redução do consumo de energia total, pois seu fator de equivalência desse insumo é alto e seu consumo expressivo.

A modificação de vazão do gás natural nos modos lança gerou redução de 8,62\% no consumo de gás natural, sem aparente perda de coerência do jato, pois não houve geração anormal de respingos de aço/escória e as taxas de descarburação se mantiveram constantes. Essa última pôde ser evidenciada pela baixa variação do teor de carbono das amostras retiradas antes do vazamento em todas as corridas. Se houvesse uma menor eficiência na descarburação, seria esperado que, com o mesmo consumo de oxigênio, houvesse um aumento no teor de carbono ao final da corrida. Segundo Mahoney [7], a perda de penetração em ambientes a alta

* Contribuição técnica ao 450 Seminário de Aciaria - Internacional, 25 a 28 de maio de 2014, Porto Alegre, RS, Brasil. 
temperatura quando se utiliza vazão de gás natural igual a 5\% da vazão de oxigênio principal é pequena se comparada com a penetração máxima alcançada com $10 \%$ da vazão de oxigênio principal (Figura 7). No entanto, em termos de consumo de gás natural, quando se utiliza uma situação ou outra, há alterações muito significativas.

O consumo de gusa e sucata, que quantifica o rendimento metálico, sofreu alterações nos três cenários, porém o $\mathrm{FeO}$ da escória não apresentou diferença significativa em todos eles. Dessa forma, as alterações no rendimento podem ser atribuídas a mudanças não controláveis na composição da carga fria utilizada como, por exemplo, seu teor de impurezas.

As variações no consumo de coque injetado são resultantes de variações naturais do processo. Apesar da alta redução percentual no cenário 2, por exemplo, 0 impacto no consumo de energia total é baixo, visto que o consumo específico desse insumo é muito baixo.

O consumo de eletrodos se manteve constante durante todo período de testes.

As duas modificações quando utilizadas conjuntamente (cenário 4) resultaram em redução de $2,38 \%$ no consumo de energia total, impulsionada principalmente pelas reduções no consumo de energia elétrica e consumo de gás natural.

\section{CONCLUSÕES}

Através dos resultados obtidos no estudo foi possível concluir que:

- O cenário 4, onde foram aplicadas as duas modificações propostas no teste, apresentou a maior redução no consumo de energia total $(2,38 \%)$;

- Os principais fatores que contribuíram para a redução do consumo de energia total foram as reduções no consumo de energia elétrica e no consumo de gás natural;

- $\mathrm{O}$ aumento da relação $\mathrm{O}_{2} / \mathrm{GN}$ de $2: 1$ para 3,5:1 resultou em redução no consumo de energia elétrica maior que $1 \%$ nos dois cenários em que foi testada;

- Com a redução da vazão de gás natural ao utilizar relação $\mathrm{O}_{2} / \mathrm{GN}$ de 3,5:1, houve redução de 9,32\% no consumo de gás natural;

- Utilizando vazão de gás natural nos modos lança igual a 5\% da vazão de oxigênio principal, houve redução de $8,62 \%$ no consumo de gás natural e não foi evidenciada perda significativa de coerência do jato;

- As alterações na composição da escória, principalmente FeO, e no carbono de vazamento não foram significativas. Isso evidencia que os ganhos energéticos vieram de uma melhor combustão dos gases e fusão da sucata dentro do forno e não através da queima de ferro da sucata e/ou carbono dos eletrodos.

\section{REFERÊNCIAS}

1 Opfermann A, Riedinger D. Energy efficiency of electric arc furnaces. In: AISTech Proceedings; 2008; Pittsburgh; EUA. Pittsburgh: Association for Iron and Steel Technology; 2008. p.795-808.

2 Fortes R. Mass and energy balance for EAF. Sapucaia do Sul: Gerdau; 2010.

3 Libório A. Melhoria no desempenho dos injetores supersônicos em operação em um forno elétrico a arco [dissertação de mestrado]. Porto Alegre: PPGEM, UFRGS; 2009.

4 UCAR. Electric Arc Furnace Digest. Houston: UCAR, 2001: 22.

5 Opfermann A, Riedinger D. Energy efficiency of electric arc furnace. In: 35th McMasters University Symposium on Iron and Steelmaking; 2007; Ontario, Canada. McMasters University; 2007. p.1-24.

* Contribuição técnica ao 45 Seminário de Aciaria - Internacional, 25 a 28 de maio de 2014, 


\section{ACJARIA}

6 Mathur P, Messina C. Praxair CoJet technology - principles and actual results from recent installations. In: 78 ${ }^{\text {th }}$ AISTech 2001 Proceedings; 2001. AIST; 2001. v.78, p.2125.

7 Mahoney WJ. Experimental remarks on supersonic jet behavior in high-temperature, reactive ambient in connection to steelmaking. In: AISTech 2010 Proceedings; 2010. AIST; 2010. v.1, p.1071-81.

8 Thompson MJ, Kournetas NG, Evenson E, Sommerville ID, Mclean A, Guerard J. Effect of oxyfuel burner ratio changes on energy efficiency in electric arc furnace at Co-Steel Lasco. Ironmaking and Steelmaking. 2001;28(3):266-72.

* Contribuição técnica ao 450 Seminário de Aciaria - Internacional, 25 a 28 de maio de 2014, Porto Alegre, RS, Brasil. 